\title{
Modeling giant-iceberg drift under the influence of sea ice in the Weddell Sea, Antarctica
}

\author{
Ghristoph Lighey, Hartmut H. Hellmer \\ Alfred Wegener Institute for Polar and Marine Research, P.O. Box 120161, D-27515 Bremerhaven, Germany
}

\begin{abstract}
The drift trajectory of giant iceberg C-7 traversing the Weddell Sea, Antarctica, for $>2$ years was successfully simulated. Application of the "classical" driving forces like wind and ocean currents resulted in a significant discrepancy between modeled and observed iceberg velocities in the western Weddell Sea. The most realistic drift pattern in space and time was achieved by adding a sea-ice force which represents the ability of a dense sea-ice cover $(\geq 90 \%)$ to lock in icebergs and collect the momentum of the wind over an area much larger than the area of the iceberg proper. This process was parameterized using a sea-ice strength $P$ which depends on sea-ice concentration and thickness, both having highest values in winter and in the western Weddell Sea which is covered with multi-year sea ice. As a consequence of the sensitivity to sea ice, the timing of the iceberg drift becomes important, revealing the region off Brunt Ice Shelf (eastern Weddell Sea) as a location where bergs either continue westward with the coastal current or follow a southern branch onto the shallow continental shelf.
\end{abstract}

\section{INTRODUCTION}

Icebergs released at a rate of $\sim 2000 \mathrm{Gt} \mathrm{a}^{-1}$ (Jacobs and others, 1992) from ice shelves of different sizes, glacier tongues and coastal calving fronts of Antarctica may influence the physical and biological environment of the Southern Ocean. The fresh-water input due to melting stabilizes the weakly stratified polar water column, hence hampering deep-ocean convection and the formation of dense water masses. If originating from deep iceberg bases, this fresh-water flux can be associated with an enhanced heat transfer to the surface (Jenkins, 1999). The release of material, collected by the inland ice on its advance toward the coast, associated with melting provides nutrients for the ocean's euphotic zone and leaves sediment patterns on the sea floor that can be used for geological and paleo-climate studies. Stranded icebergs can "plough" the sea floor, causing long-term disturbances of the local ecosystem (Gutt and Starmans, 2001). Finally, drifting icebergs threatened sailing ships circumnavigating the southern tip of South America (Kozian, 1994); nowadays, they may

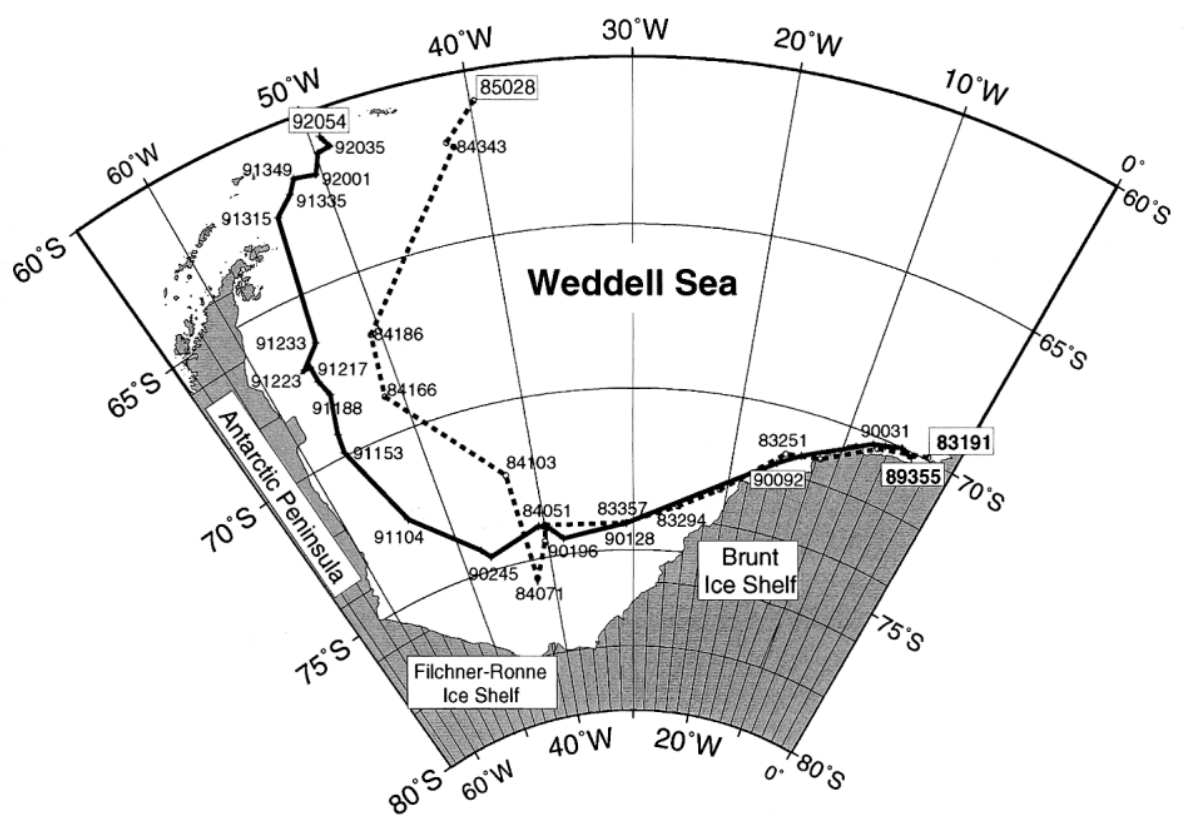

Fig. 1. Drift of icebergs C-7 (solid line) and B-4 (dashed line) through the Weddell Sea from the 355th day of 1989 until the 54 th day of 1992, and from the 191st day of 1983 until the 28 th day of 1985, respectively, as observed by the U.S. National Ice Center. Sights are labeled by date (yy/ddd). Collision with the eastern Weddell Sea coast is an artifact due to uncertain coastline coordinates used by the plotting routine. 
be a problem for research and tourist ships operating more frequently in Antarctic waters.

This study focuses on the relative importance of atmosphere, ocean and sea-ice forces acting on a "giant" iceberg (edges longer than 10 nautical miles $(18.5 \mathrm{~km})$ ) drifting through the Weddell Sea. Including sea ice as an active component of the iceberg drift rather than a passive one (Viehoff and Li, 1995) was motivated by the observations during the drift of Ice Station Weddell (ISW-1) which indicated that, at high sea-ice concentrations, icebergs move with the pack ice. With the focus on the dynamics rather than thermodynamics, we ignore iceberg melting, justified by the model results that drift trajectories did not change significantly for different $(100-400 \mathrm{~m})$ iceberg drafts. The impact of the fresh-water input due to melting on water-column stability, deep convection and the formation of deep and bottom water participating in the global thermohaline circulation is the subject of ongoing research.

Model results are compared with the observed drift of iceberg C-7, which was first seen in the western Pacific/ eastern Indian sector of the Southern Ocean. For $>2$ years C-7 drifted through the Weddell Sea at a mean velocity of $0.11 \mathrm{~m} \mathrm{~s}^{-1}$ following closely the path of the coastal current (Fig. 1). Though other bergs like B4 followed the same path at a slightly higher mean velocity of $0.15 \mathrm{~m} \mathrm{~s}^{-1}, \mathrm{C}-7$ was selected because its time in the Weddell Sea corresponds to the period (1985-93) from which atmospheric data were used to drive the sea-ice and ocean circulation models. The latter provided the oceanic forcing component for the iceberg-drift model. The characteristics of iceberg C-7 are listed in Table 1.

\section{FORCES}

The basic equation describing iceberg motion in icecovered seas includes the forces due to air drag $\left(\vec{F}_{\mathrm{A}}\right)$, and water drag $\left(\vec{F}_{\mathrm{W}}\right)$, the Coriolis force $\left(\vec{F}_{\mathrm{C}}\right)$, the slope of the sea surface $\left(\vec{F}_{\mathrm{SS}}\right)$ and the force due to the interaction with the sea-ice cover $\left(\vec{F}_{\mathrm{SI}}\right)$ :

$$
M \frac{\mathrm{d} \vec{u}}{\mathrm{~d} t}=\vec{F}_{\mathrm{A}}+\vec{F}_{\mathrm{W}}+\vec{F}_{\mathrm{C}}+\vec{F}_{\mathrm{SS}}+\vec{F}_{\mathrm{SI}}
$$

where $M$ is the mass and $\vec{u}$ is the velocity of the iceberg. All terms on the righthand side are evaluated for an iceberg considered as a point mass with finite area.

The drags $\left(\vec{F}_{\mathrm{A}}\right.$ and $\left.\vec{F}_{\mathrm{W}}\right)$, considered as the sum of the forces acting on vertical walls (form drag) and horizontal

Table 1. Characteristics of iceberg C-7

\begin{tabular}{lc}
\hline Variable & Value \\
\hline Length & $27780 \mathrm{~m}$ \\
Draft & $200 \mathrm{~m}$ \\
Thickness & $225 \mathrm{~m}$ \\
Mass & $1.597 \times 10^{14} \mathrm{~kg}$ \\
$A_{\mathrm{h} x}$ & $7.717 \times 10^{8} \mathrm{~m}^{2}$ \\
$A_{\mathrm{vW}}$ & $5.556 \times 10^{6} \mathrm{~m}^{2}$ \\
$A_{\mathrm{vA}}$ & $6.945 \times 10^{5} \mathrm{~m}^{2}$ \\
\hline
\end{tabular}

Notes: $A_{\mathrm{h} x}$ is the horizontal area in contact with air $(\mathrm{A})$ or water $(\mathrm{W})$, and $A_{\mathrm{vW}}$ and $A_{\mathrm{vA}}$ are the surfaces perpendicular to oceanic and atmospheric flow, respectively, calculated for a square iceberg with a length of $15 \mathrm{~nm}$ $(1 \mathrm{~nm}=1852 \mathrm{~m})$. The latter represents the mean of the original size $(10 \mathrm{~nm} \times 20 \mathrm{~nm})$ based on measurements from satellite images, while all other values were estimated. surfaces (skin drag), are determined by the general drag relationship (e.g. Smith and Banke, 1983):

$$
\vec{F}_{x}=\left[\frac{1}{2}\left(\rho_{x} c_{x} A_{\mathrm{v} x}\right)+\left(\rho_{x} c_{\mathrm{d} x} A_{\mathrm{h} x}\right)\right]\left|\vec{v}_{x}-\vec{u}\right|\left(\vec{v}_{x}-\vec{u}\right),
$$

where $\rho_{x}$ is the medium density, $c_{x}$ is the dimensionless coefficient of resistance, set to $c_{\mathrm{W}}=0.85$ for water and $c_{\mathrm{A}}=0.4$ for air, $c_{\mathrm{d} x}$ is the dimensionless drag coefficient for very smooth surfaces, set to $c_{\mathrm{dW}}=5 \times 10^{-4}$ for water and $c_{\mathrm{dA}}=2.5 \times 10^{-4}$ for air, $A_{\mathrm{v} x}\left(\mathrm{~m}^{2}\right)$ is the area of the iceberg wall facing the air/water flow, $A_{\mathrm{h} x}\left(\mathrm{~m}^{2}\right)$ is the area of the horizontal iceberg surfaces in contact with the wind (top) and ocean current (base), and $\vec{v}_{x}\left(\mathrm{~m} \mathrm{~s}^{-1}\right)$ is the wind/ocean current velocity; here, $x$ refers to air (A) and water (W). The densities of air and water are assumed to be constant at $\rho_{\mathrm{A}}=1.293\left(\mathrm{~kg} \mathrm{~m}^{-3}\right)$ and $\rho_{\mathrm{W}}=1027.5\left(\mathrm{~kg} \mathrm{~m}^{-3}\right)$. The water velocity $\vec{v}_{\mathrm{W}}$ results from the vertical integration of the top layers of the ocean circulation model BRIOS-1 (Bremerhaven Regional Ice-Ocean Simulations; Beckmann and others, 1999), starting at the sea surface down to the draft of the iceberg. The wind velocity $\vec{v}_{\mathrm{A}}$ is obtained from the $10 \mathrm{~m}$ winds of the U.S. National Centers for Environmental Prediction/ U.S. National Center for Atmospheric Research (NCEP/ NCAR) Re-analysis Project (Kalany and others, 1996).

The drift of icebergs is also influenced by the Coriolis force which leads in the Southern Hemisphere to a deflection to the left according to:

$$
\vec{F}_{\mathrm{C}}=2 M \Omega \sin \phi \vec{k} \times \vec{u},
$$

where $\Omega$ is the rotation of the Earth $\left(\Omega=7.27 \times 10^{-5} \mathrm{~s}^{-1}\right), \phi$ is the latitude, $\vec{k}$ is the unit vector perpendicular to the Earth's surface and $\vec{u}$ is the iceberg velocity.

The force acting on icebergs due to the slope of the sea surface is defined by:

$$
\vec{F}_{\mathrm{SS}}=-M \vec{g} \sin \alpha,
$$

where $\vec{g}$ is the acceleration due to gravity and $\alpha$ is the tilt of the sea surface estimated from the barotropic part of the modeled ocean velocity (Beckmann and others, 1999). A good approximation is the geostrophically balanced mean velocity of the entire water column relative to the flow at $\sim 1000$ m depth.

Sea-ice extent and concentration in the Weddell Sea are subject to large seasonal variations. Therefore, the force due to sea ice is split for three categories of sea-ice concentration:

$$
\begin{gathered}
\vec{F}_{\mathrm{SI}} \\
=\left\{\begin{array}{c}
0: A \leq 15 \% \\
\frac{1}{2} \rho_{\mathrm{SI}} c_{\mathrm{SI}} A_{\mathrm{SI}}\left|\vec{v}_{\mathrm{SI}}-\vec{u}\right|\left(\vec{v}_{\mathrm{SI}}-\vec{u}\right): 15 \%<A<90 \% \\
-\left(\vec{F}_{\mathrm{A}}+\vec{F}_{\mathrm{W}}+\vec{F}_{\mathrm{C}}+\vec{F}_{\mathrm{SS}}\right): A \geq 90 \% \text { and } P \geq P_{\mathrm{S}}
\end{array}\right.
\end{gathered}
$$

where $A(\%)$ is the sea-ice concentration, $P\left(\mathrm{~N} \mathrm{~m}^{-1}\right)$ is the sea-ice strength and $P_{\mathrm{s}}\left(\mathrm{N} \mathrm{m}^{-1}\right)$ is a threshold value (see below). Sea-ice concentrations lower than $15 \%$ are considered as open water with no additional force acting on the iceberg, $\vec{F}_{\text {SI }}=0$. For sea-ice concentrations of $15-90 \%$, sea ice acts as an additional drag using a coefficient of resistance of $c_{\mathrm{SI}}=1.0$, and $A_{\mathrm{SI}}$ as the product of sea-ice thickness and iceberg width. For sea-ice concentrations $\geq 90 \%$, iceberg and sea ice form a solid block which can occur during austral winter in the inner 


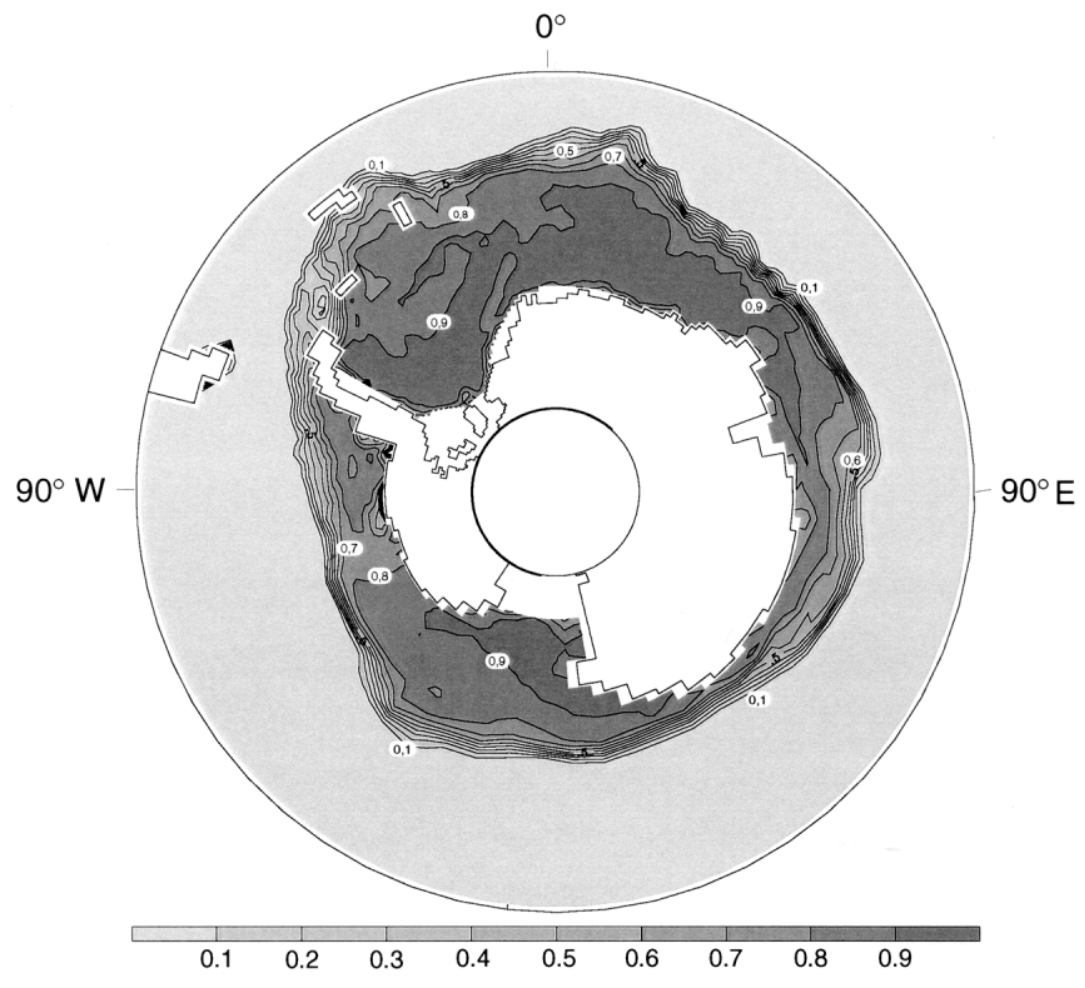

Fig. 2. Monthly mean sea-ice concentration in the Southern Ocean derived from Special Sensor Microwave/Imagerdata for September 1987, a maximum in sea-ice extent (Heygster and others, 1996). Contour interval is 0.1 (=10\%).

Weddell Sea (Fig. 2). In this case, the sum of the forces is set to zero, i.e. the iceberg does not accelerate but will drift, as a first approximation, with the sea-ice velocity calculated by the stand-alone sea-ice model BRIOS-0 (Beckmann and others, 1999).

A measure for the resistance of the sea ice is the sea-ice strength which is given by the relationship:

$$
P=P^{*} h \exp [-20(1-A)]
$$

according to Hibler (1979), where $h$ is the sea-ice thickness per unit area, $A$ is the sea-ice concentration and $P^{*}$ is an empirical coefficient ranging from 15000 to $30000 \mathrm{~N} \mathrm{~m}^{-2}$, with 20000 $\mathrm{N} \mathrm{m}^{-2}$ as the preferred value (personal communication from R. Timmermann, 2000). Spatial and temporal coverage of seaice concentration $(A)$ and thickness $(h)$ are provided by the BRIOS-0 sea-ice model (Beckmann and others, 1999). The threshold value $\left(P_{\mathrm{s}}\right)$ at which sea ice resists the forces acting on an iceberg without breaking has been calculated according to Equation (5). We used the characteristics of iceberg C-7 listed in Table 1, and extreme values for wind velocity (5-25 m s${ }^{-1}$; Crepon and Houssais, 1988) and ocean current (0.05-0.20 $\mathrm{m} \mathrm{s}^{-1}$; Muench and Gordon, 1995) representative for the western Weddell Sea, but neglected the forces due to Earth rotation and surface slope. The force per unit length ranges from 660.9 to $14211.6 \mathrm{~N} \mathrm{~m}^{-1}$ for typical and strong (water/air) flows, respectively, equivalent to the range of minimum values for the sea-ice strength $P$.

The minimum sea-ice thickness $h_{\min }$ able to lock in an iceberg for a given sea-ice concentration $A$ and sea-ice strength $P$ follows from Equation (6) to:

$$
h_{\text {min }}=\frac{P}{P^{*} \exp [-20(1-A)]} .
$$

For typical flows $\left(P=660.9 \mathrm{~N} \mathrm{~m}^{-1}\right)$, the minimum thickness $h_{\text {min }}$ reduces from $h=0.24 \mathrm{~m}$ at $A=90 \%$ to $h=$ $0.03-0.04 \mathrm{~m}$ at $A=100 \%$, while for strong flows $(P=$ $\left.14211.6 \mathrm{~N} \mathrm{~m}^{-1}\right) h_{\text {min }}$ decreases from $h=5.0 \mathrm{~m}$ to $h=0.70 \mathrm{~m}$ for the same range of sea-ice concentration (Fig. 3). Sea-ice thickness observations (Haas and others, 1992; Drinkwater and Haas, 1994) from the Winter Weddell Gyre Study (Lemke, 1994) showed a mean ice thickness of $0.88 \mathrm{~m}$. Since this value is well above the calculated minimum ice thickness for typical flows, icebergs can frequently be locked by sea ice in the Weddell Sea. However, it should be noted that only forces were considered which are parallel to the sea-ice plane. Shear and bending forces, which occur due to iceberg

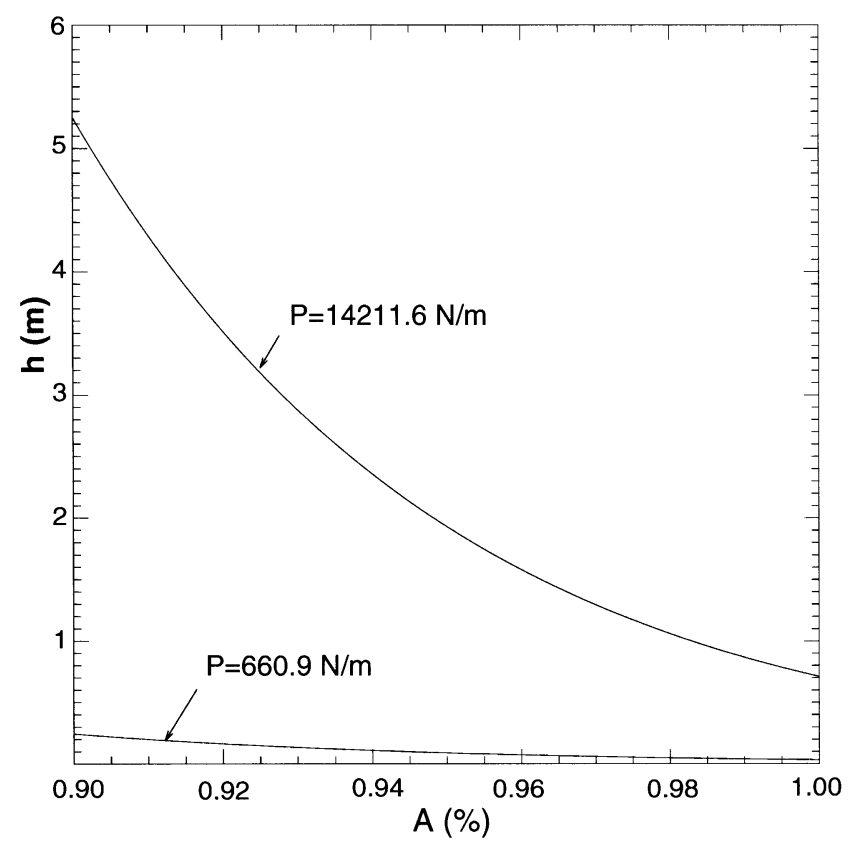

Fig. 3. Sea-ice thickness $h$ vs sea-ice concentration A (90$100 \%$ ), typical for winter months in the inner Weddell Sea (Fig. 2), for sea-ice strengths $P=660.9 \mathrm{Nm}^{-1}$ and $P=$ $14211.6 \mathrm{~N} \mathrm{~m}^{-1}$. 


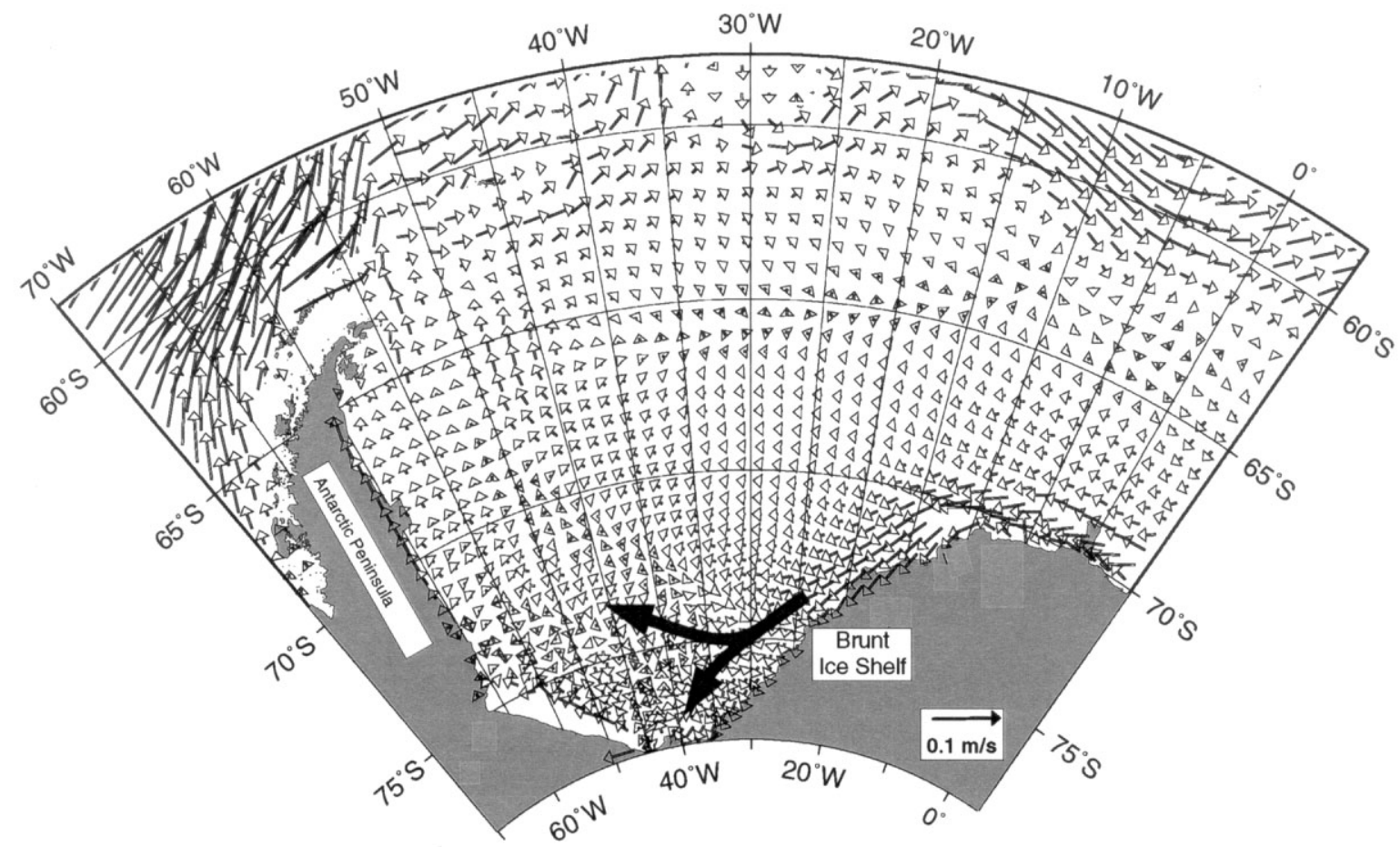

Fig. 4. Annual mean (21st year) of modeled (BRIOS-1) ocean velocity integrated over the top $200 \mathrm{~m}$ for the Weddell Sea sector.

Thick arrowes represent the bifurcation of the coastal current off the Brunt Ice Shelf.

tilt and rotation, have been neglected. Therefore, the calculated minimum ice thicknesses should be treated as a lower bound of the sea ice's ability to capture icebergs.

The iceberg-drift trajectory is calculated using an Eulerian forward scheme with a constant time-step of $\delta t=$ 600 s. Different time-steps were tested, and the results compared with the observed drift of iceberg C-7. The displacement of the iceberg occurs in the geographic coordinate space of $\phi$ and $\lambda$ to which all the forcing data are interpolated.

\section{FORGING DATA}

The iceberg-drift model requires velocity fields of the ocean, the atmosphere and the sea ice, with additional information about sea-ice thickness and concentration to calculate the sea-ice strength.

The ocean velocity fields are provided by the numerical ocean-circulation model BRIOS-1 (Beckmann and others, 1999), developed to study the large-scale structure of the Weddell Gyre and the importance of various processes and regions for the formation and spreading of deep and bottom waters. BRIOS-1 is a stand-alone coarse-resolution circulation model with a circumpolar grid focused on the Weddell Sea sector. The velocity data from the 21st year of the standard simulation, available in 3 day intervals, are vertically integrated over the $200 \mathrm{~m}$ draft of the model iceberg. The resulting velocity field shows the dominance of the cyclonic Weddell Gyre, with intensification at its southern and western boundary representing the coastal current, and a bifurcation of the latter off the Brunt Ice Shelf (Fig. 4). One branch flows westward along the continental slope; the other penetrates southward onto the continental shelf where no predominant circulation pattern exists other than the flow parallel to the Filchner-Ronne Ice Shelf edge.

Sea-ice concentration, thickness and drift velocity originate from a stand-alone dynamic-thermodynamic sea-ice/mixed- layer model (BRIOS-0) which is based on the formulations of Hibler (1979) and Lemke and others (1990). BRIOS-0 also provided the surface fluxes (momentum, heat and fresh-water) for the ocean circulation model BRIOS-1. This guarantees that the forcing due to both sea ice and ocean is consistent for the iceberg drift model.

The atmospheric forcing results from the $2 \mathrm{~m}$ wind velocity fields of the NCEP Re-analysis Project, used as 3 day averages of the C-7 drift period (December 1989February 1992). This high resolution in time guarantees that the seasonal signal with increasing winds during austral winter is included.

\section{RESULTS}

A series of simulations was conducted, all releasing an ensemble of icebergs with the parameters of C-7 (Table 1) along the Greenwich Meridian (GM) between $70^{\circ}$ and $67.8^{\circ} \mathrm{S}$, displaced meridionally by $0.2^{\circ}$, on the 350 th day of 1989. The first series examines the sensitivity of the drift trajectories to the threshold value $P_{\mathrm{s}}$ of ice strength $P$, applying all driving forces. The second series reveals the relative importance of the different drivings by deactivating each single force, and the third studies the influence of the time/season of iceberg release at the GM. All experiments include some examination of the spatial variability due to the meridional stretching of the iceberg release.

\subsection{Influence of sea-ice strength}

The threshold value $P_{\mathrm{s}}$, depending on sea-ice thickness and concentration (Equation (6)), determines when an iceberg moves with the sea ice. We conducted three simulations using the minimum value of $P_{\mathrm{s}}=660 \mathrm{~N} \mathrm{~m}^{-1}$, and values around the maximum with $P_{\mathrm{s}}=13000 \mathrm{~N} \mathrm{~m}^{-1}$ and $P_{\mathrm{s}}=$ $16000 \mathrm{~N} \mathrm{~m}^{-1}$ (Fig. 5a-c). Assuming ice thicknesses of 0.8-1.0 $\mathrm{m}$ for the western/northwesternWeddell Sea (Massom 

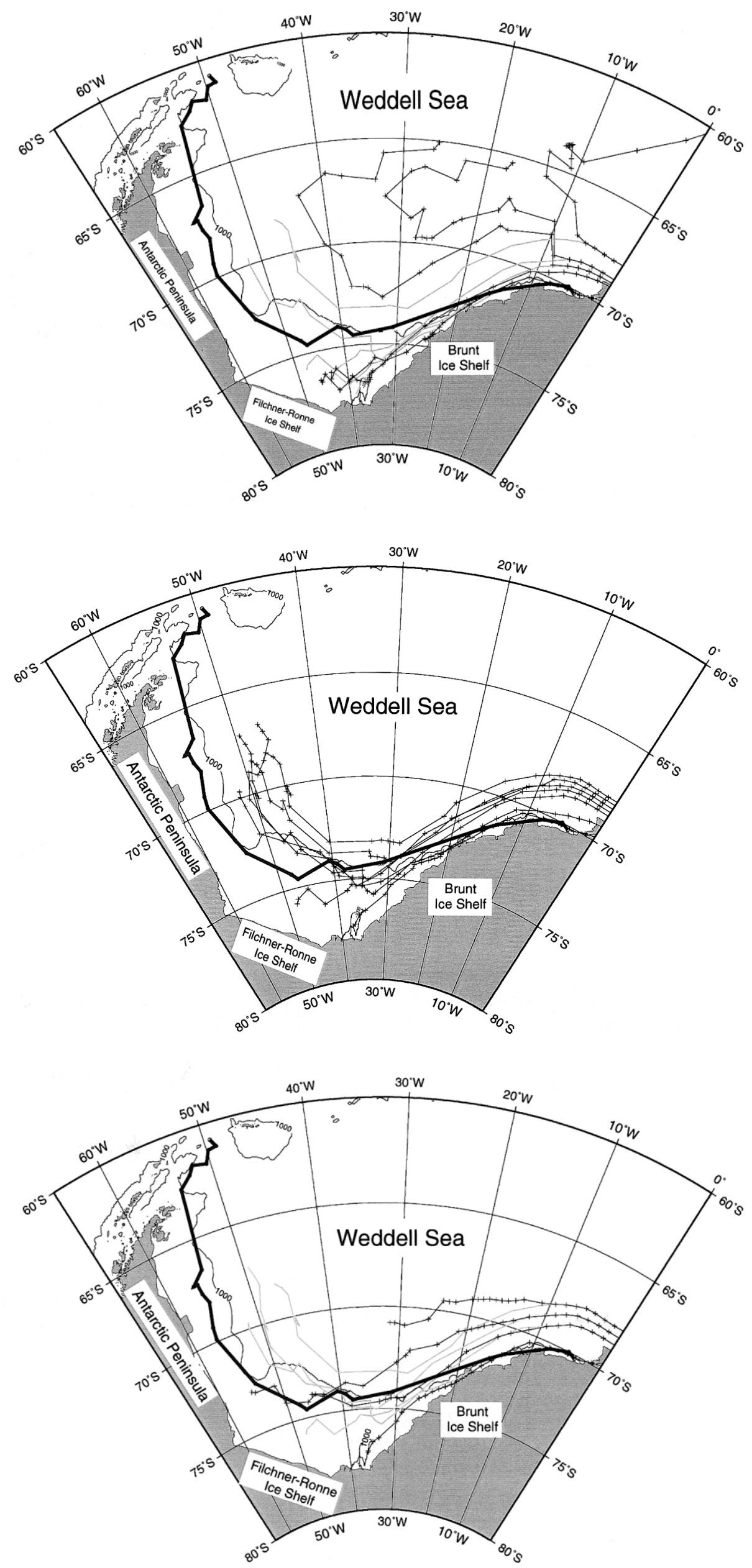

Fig. 5. Representative drift trajectories of an ensemble of icebergs using the threshold values $P_{\mathrm{s}}=660 \mathrm{~N} \mathrm{~m}^{-1}$ (a), $P_{\mathrm{s}}=13000 \mathrm{Nm}^{-1}$ (b) and $P_{\mathrm{s}}=16000 \mathrm{~N} \mathrm{~m}^{-1}(\mathrm{c})$. Crosses mark modeled positions every 30 days. The thick solid line indicates the drift of $C-7$; observed positions are marked with circles. The grey lines in (a) and (c) correspond to the simulation with $P_{\mathrm{s}}=13000 \mathrm{Nm}^{-1}$. 


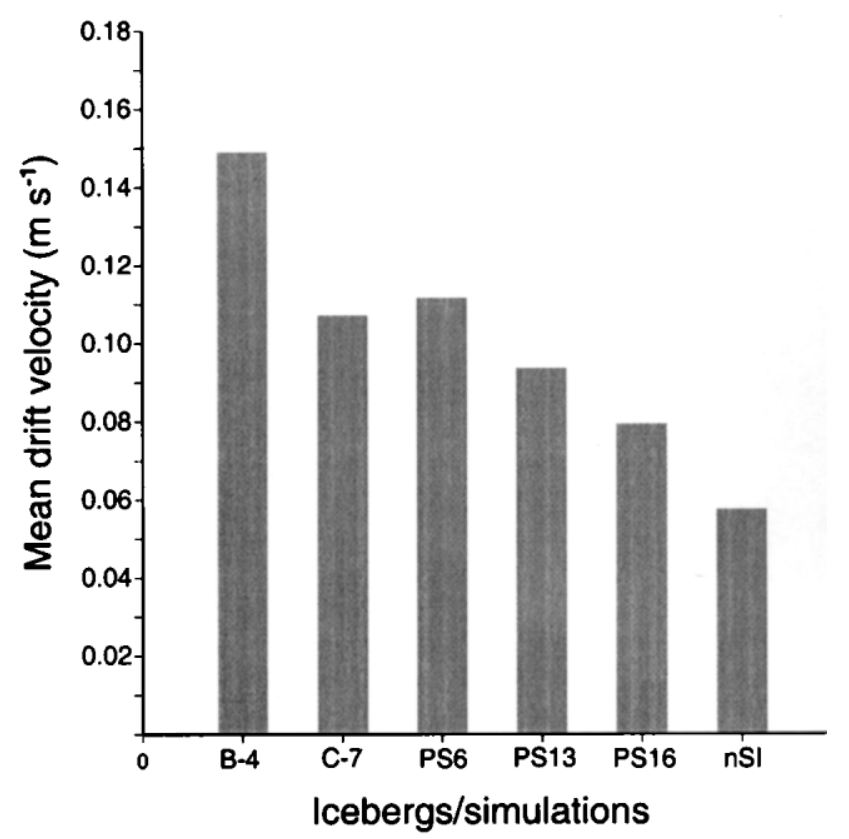

Fig. 6. Mean drift velocities of observed ( $B-4$ and $C-7)$ and modeled icebergs in the Weddell Sea. Simulations were conducted with threshold values of $660 \mathrm{~N} \mathrm{~m}^{-1}$ (PS6), 13000 $\mathcal{N m}^{-1}$ (PS13), $16000 \mathrm{Nm}^{-1}$ (PS16) and without sea-ice forcing $(n S I)$. The modeled mean velocity represents the ensemble's mean.

and others, 1997), this $P_{\mathrm{s}}$ range corresponds to sea-ice concentrations of $84-100 \%$.

In all simulations icebergs drift westward into the inner Weddell Sea, indicating the westward direction of the forces in atmosphere and ocean, the latter as part of the southern branch of the cyclonic Weddell Gyre (Fahrbach and others, 1994; Schroder and Fahrbach, 1999). Icebergs with the southernmost release closely follow the coastline, being captured by the sluggish circulation on the southern Weddell Sea continental shelf towards the end of the simulation. For $P_{\mathrm{s}}$ values even higher (not shown), this drift pattern does not change since sea-ice concentrations in a narrow band off the eastern Weddell Sea coast do not exceed 90\% (Fig. 2), allowing icebergs to interact but not to drift solely with the sea ice (Equation (5)). Icebergs released further north clearly show a drift that depends on the threshold value. For low $P_{\mathrm{s}}$, icebergs are more easily caught in the sea ice following trajectories similar to those of deployed sea-ice drifters, which show periods of slow to stagnant drift along $10^{\circ} \mathrm{W}$ (Kottmeier and Sellmann, 1996). The tendency of northerly flow outside the coastal current is also visible in modeled surface drift trajectories as part of the eastern cell of the Weddell Gyre (Beckmann and others, 1999). At higher values, the atmospheric/oceanic forcing dominates more, allowing farther penetration into the Weddell Sea with the coastal current.

The simulations show that the iceberg drift strongly depends on sea-ice characteristics and their spatial distribution, superimposed on the "background" forcing of atmosphere and ocean. While high sea-ice concentrations in the eastern Weddell Sea reduce iceberg velocities relative to a strong coastal current (Fahrbach and others, 1994), a closed sea-ice cover accelerates drift in the western Weddell Sea where the coastal current is weaker (Muench and Gordon, 1995). The best model results with respect to the drift pattern (Fig. 5b) and mean velocity (Fig. 6) of iceberg C-7 in the Weddell Sea are obtained with a threshold value of $P_{\mathrm{s}}=13000 \mathrm{~N} \mathrm{~m}^{-1}$, which has therefore been used for all following simulations. The simulation with $P_{\mathrm{s}}=660 \mathrm{~N} \mathrm{~m}^{-1}$ provided a mean velocity closer to the observed, but this threshold value has been rejected because of major discrepancies in the drift pattern (Fig. 5a).

\subsection{Relative importance of the driving forces}

The influence of the forces of wind, ocean currents and sea ice on the iceberg drift is examined by deactivating each single force in Equation (1) but always applying the acceleration due to Coriolis force and sea-surface slope.

The experiment without wind forcing (Fig. 7) shows drift trajectories similar to the results with all forces activated (Fig.

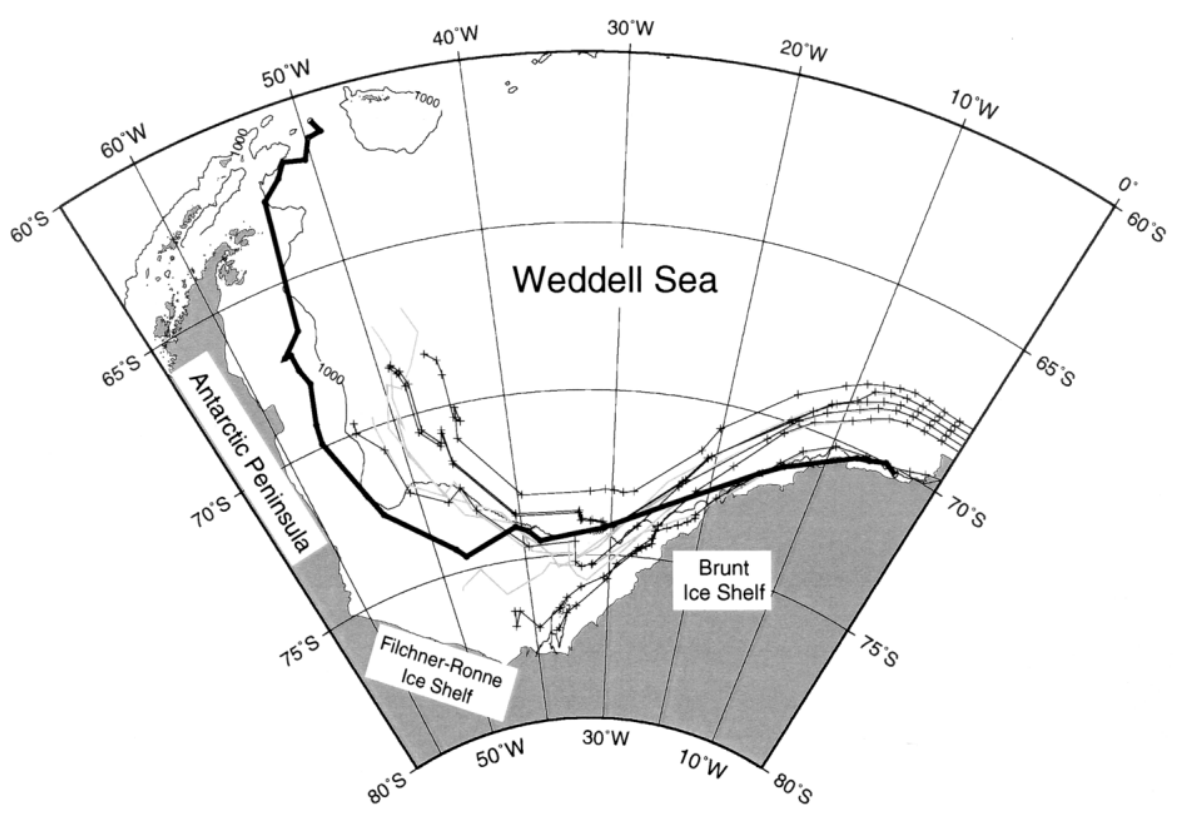

Fig. 7. Representative drift trajectories of an ensemble of icebergs forced by ocean currents, sea ice (threshold value $P_{\mathrm{s}}=13000 \mathrm{Nm}^{-1}$ ), Coriolis and sea-surface slope, but without wind. Crosses mark the position every 30 days. The thick solid line indicates the drift of $C$-7, observed positions are marked with circles, and the grey lines correspond to the modeled trajectories of icebergs forced with all forcing components and a threshold value of $P_{\mathrm{s}}=13000 \mathrm{~N} \mathrm{~m}^{-1}$ (Fig. $5 b$ ). 


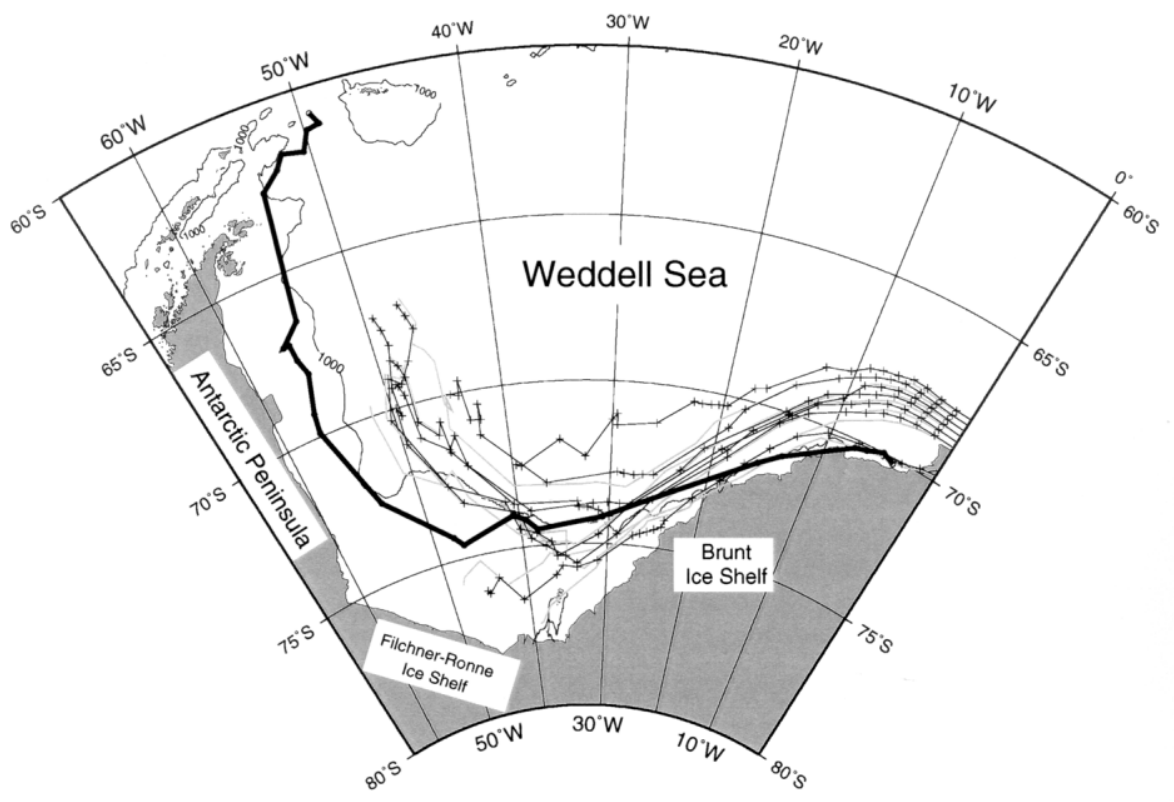

Fig. 8. Representative drift trajectories of an ensemble of icebergs forced by wind, sea ice (threshold $P_{\mathrm{S}}=13000 \mathrm{~N} \mathrm{~m}^{-1}$ ), Coriolis and sea-surface slope, but not ocean currents $\left(\vec{u}_{\mathrm{W}}=0\right)$. Thick solid line represents the drift of $C$-7.

5b). This suggests that the importance of the wind is minor. However, the experiment only excludes the wind acting directly on the iceberg, while a substantial part is indirectly transferred to the berg via the fact that ocean circulation and sea-ice drift are primarily wind-driven. The following experiments will show that in ice-covered regions sea ice is a more efficient "collector" of this momentum.

In examining the influence of ocean currents on the iceberg drift, one would tend to neglect the ocean forcing $\left(F_{\mathrm{W}}\right)$ in Equation (1). However, this would result in unrealistically high iceberg velocities $\vec{u}$ because of the lack of friction between water and iceberg. This drag, due to the order-of-magnitude difference in density, is equal to the air/ iceberg drag $\left(F_{\mathrm{A}}\right)$ at lower relative velocities (Equation (2)). Therefore, the ocean velocity was set to zero $\left(\vec{v}_{\mathrm{W}}=0\right)$ to examine the importance of ocean currents. The similarity of the trajectories to those of the simulation with oceanic forcing (black vs gray lines in Fig. 8) indicates that the influence of ocean currents, driven by the wind, on iceberg drift is minor in ice-covered seas. This implies that wind momentum is transformed into iceberg movement most efficiently via the sea-ice cover.

Finally, to examine the influence of sea ice on the iceberg drift, the force due to sea ice $\left(F_{\mathrm{SI}}\right)$ has been deactivated. The significantly slower drift velocities, especially when approaching the seasonally ice-covered central and southwestern Weddell Sea (Fig. 9), show the importance of sea ice for simulating realistic iceberg drifts. As for the ocean, neglecting the sea-ice force suppresses much of the wind forcing. In addition, both forces are strongly correlated, i.e. winds are strong when sea-ice concentration peaks (austral winter) and the ice is able to "collect" the wind momentum over vast areas. This points to the importance of the time/season when icebergs reach certain locations in the sea-ice-dominated Weddell Sea. Adding the friction between iceberg and sea ice but neglecting its total lock-in does not change the drift pattern shown in Figure 9.

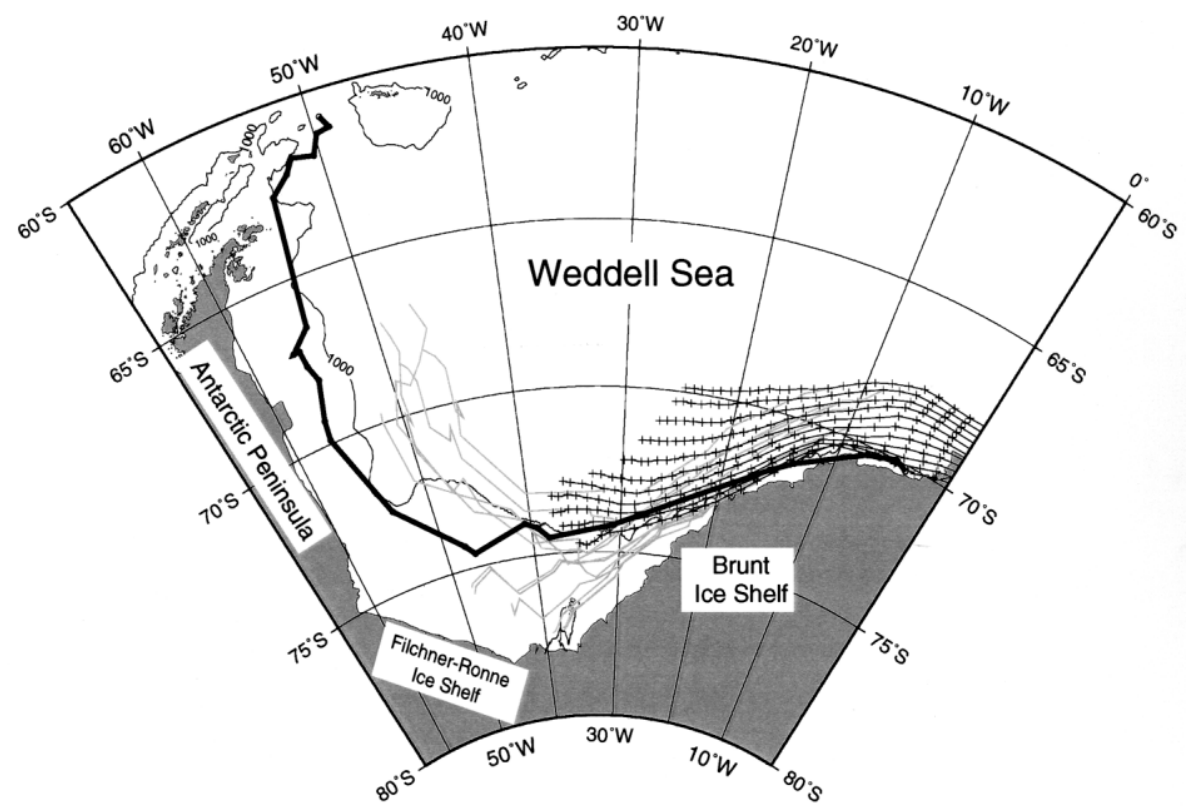

Fig. 9. Representative drift trajectories of an ensemble of icebergs forced by ocean currents, wind, Coriolis and sea-surface slope, but not sea ice. Thick solid line represents the drift of $C-7$. 


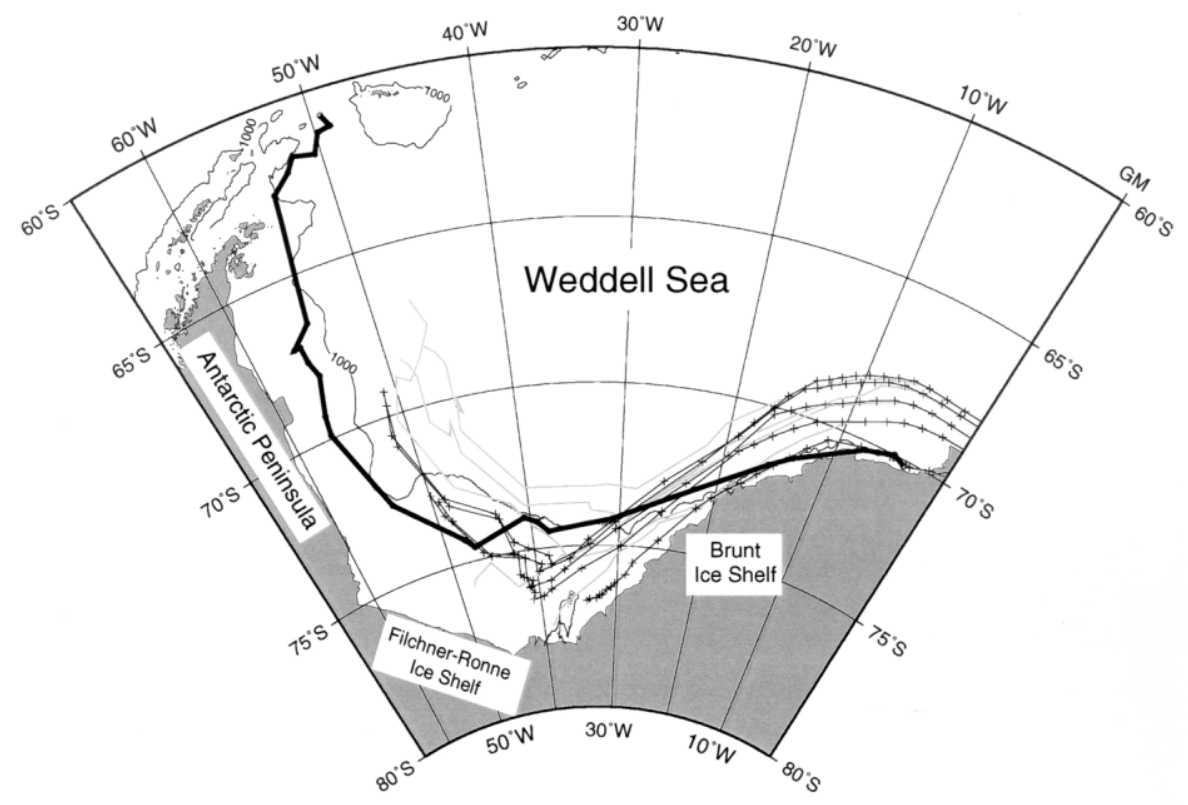

Fig. 10. Representative drift trajectories of an ensemble of icebergs driven by all forces but icebergs started at the GM on the 170th day of 1989 ( beginning of austral winter). Thick solid line represents the drift of $C-7$.

This indicates that a sea-ice cover, if solid ( $\geq 90 \%)$, compensates for a slow-down of the ocean due to reduced air/ocean interaction.

\subsection{Seasonal variations}

All forces considered here are subject to seasonal variations, with atmosphere and especially sea ice (e.g. Gordon, 1981) showing large seasonal amplitudes. To examine the influence of the time icebergs pass the GM and arrive at certain locations in the Weddell Sea at different times of the year, icebergs were released along the GM 180 days before the standard simulation (Fig. 5b), i.e. on the 170th day of 1989, the beginning of austral winter.

Icebergs passing the GM at the beginning of winter penetrate onto the southwestern Weddell Sea continental shelf (Fig. 10) where a slower-moving sea-ice cover and/or weaker shelf circulation (Fig. 4) transports icebergs to the north/northwest (e.g. the drift of iceberg A-24 in Grosfeld and others (1998)). The key location for a different drift behavior is the sea off the Brunt Ice Shelf where "winter icebergs" arrive 1 year after their release. They continue to drift with a thickening sea-ice cover onto the continental shelf. In contrast, "summer icebergs" arriving in the eastern Weddell Sea in late winter pass the critical region without being locked in sea ice. Therefore, they follow, with a few exceptions, the coastal current toward the west. The sea-ice cover of the western Weddell Sea is then consolidated enough to transport the bergs within one winter season to the northern rim of the Weddell Sea.

\section{CONGLUSIONS}

Our study shows that it is essential to consider the dynamic interaction between an iceberg and its surrounding sea ice in models of giant-iceberg drift in order to reproduce the observed patterns. This is based on the sea ice's ability to lock in even big bergs and to collect the wind momentum over a huge area, both at high sea-ice concentrations. In our model, this ability is parameterized by the sea-ice strength $P$ which depends on sea-ice concentration and thickness. $P$ becomes important for the compact winter sea-ice cover of the whole, and the perennial sea ice of the western Weddell Sea. Simulations without the sea-ice force show a significant slow-down in iceberg velocities. The importance of the various forces is relative, as the ocean is the dominant component in regions with strong nearsurface currents and sea-ice concentrations $<90 \%$. However, the wind remains the ultimate force using media of different "efficiency" to transform the atmosphere's momentum into iceberg displacement. In addition, the timing of the iceberg's arrival at certain locations often determines its fate. Such a critical region exists in front of the Brunt Ice Shelf where the coastal current bifurcates and heavy ice can transport bergs onto the shallow Berkner Shelf. Stranded there, icebergs might have an impact on the hydrography of the whole southern Weddell Sea including the circulation beneath the Filchner-Ronne Ice Shelf (Nøst and Østerhus, 1998).

The existing differences between observed and modeled iceberg velocities in the western Weddell Sea could be reduced by applying the following improvements:

The resolution of modeled oceanic surface currents should be increased in order to better represent the dynamics of the coastal current.

Forcing data from a coupled sea-ice--ocean-atmosphere model should be used to better represent the interaction between various components of the iceberg drift.

The general threshold approach for ice strength $P$ used in this study should be replaced by a local evaluation of the forces acting on sea ice. Additionally, the constant value of $P^{*}$, set to $20000 \mathrm{~N} \mathrm{~m}^{-2}$ in this study, should be smaller for regions of melting sea ice.

The number of observations for icebergs of different sizes should be increased for model validation.

The next step will be the implementation of iceberg decay including basal and lateral melting to evaluate the fresh- 
water flux into the ocean. Weakly stratified, the latter is susceptible to deep convection, a precursor of the formation of deep water and/or polynyas (Martinson and others, 1981). Such melting would include the release of iron, supposed to be critical for the fertilization of the euphotic zone (Smetacek and others, 1997), and other incorporated material (ice-rafted debris) which might help to interpret past climate signals in sediment cores of the Southern Ocean.

\section{ACKNOWLEDGEMENTS}

We are grateful to the members of the BRIOS group, especially to A. Beckmann, G. Birnbaum and R. Timmermann, for their various contributions. The comments of K. Grosfeld and one anonymous reviewer helped to improve the original manuscript. Thanks to M. Lange for his expertise in handling the paper, and to E. Augstein for supervising C. Lichey during his diploma thesis of which this paper is an excerpt.

\section{REFERENCES}

Beckmann, A., H. H. Hellmer and R. Timmermann. 1999. A numerical model of the Weddell Sea: large-scale circulation and water mass distribution. $\mathcal{F}$. Geophys. Res., 104(C10), 23,374-23,391.

Crepon, M. and M. N. Houssais. 1988. Drift of icebergs under wind action. 7. Geophys. Res., 93(C4), 3608-3612.

Drinkwater, M. R. and C. Haas. 1994. Snow, sea-ice, and radar observations during $A \mathcal{N T}$ X/4: summary data report. Bremerhaven, Alfred Wegener Institute for Polar and Marine Research. Physics Department. (Report 53.)

Fahrbach, E., G. Rohardt, M. Schröder and V. Strass. 1994. Transport and structure of the Weddell Gyre. Ann. Geophysicae, 12(9), 840-855.

Gordon, A. L. 1981. Seasonality of Southern Ocean ice. 7. Geophys. Res., 86(C5), 4193-4197.

Grosfeld, K., H. H. Hellmer, M. Jonas, H. Sandhäger, M. Schulte and D. G. Vaughan. 1998. Marine ice beneath Filchner Ice Shelf: evidence from a multi-disciplinary approach. In Jacobs, S. S. and R. F. Weiss, eds. Ocean, ice and atmosphere: interactions at the Antarctic continental margin. Washington, DC, American Geophysical Union, 321-341. (Antarctic Research Series 75.)

Gutt, J. and A. Starmans. 2001. Quantification of iceberg impact and benthic recolonisation patterns in the Weddell Sea (Antarctica). Polar
Biol., 24(8), 615-619.

Haas, C., T. Viehoff and H. Eicken, eds. 1992. Sea-ice conditions during the Winter-Weddell-Gyre-Study 1992 ANT X/4 with RV Polarstern: shipboard observations and AVHRR satellite imagery. Alfred-Wegener-Inst. für Polarund Meeresfors., Bremerhaven, Germany, Tech. Rep. 34.

Heygster, G. and 12 others. 1996. PELICON - Project for Estimation of Long-term variability in Ice CONcentration. Final report. Bremen, University of Bremen. European Communities Environment Programme. (Contract EV5VCT93-0268.)

Hibler, W. D., III. 1979. A dynamic thermodynamic sea ice model. F. Phys. Oceanogr., 9 (7), 815-846.

Jacobs, S. S., H. H. Hellmer, C. S. M. Doake, A. Jenkins and R. M. Frolich. 1992. Melting of ice shelves and the mass balance of Antarctica. F. Glaciol., 38 (130), 375-387.

Jenkins, A. 1999. The impact of melting ice on ocean waters. F. Phys. Oceanogr., 29(9), 2370-2381.

Kalnay, E. and 21 others. 1996. The NCEP/NCAR 40-year reanalysis project. Bull. Am. Meteorol. Soc., 77(3), 437-471.

Kottmeier, Ch. and L. Sellmann. 1996. Atmospheric and oceanic forcing of Weddell Sea ice motion. 7. Geophys. Res., 101(C9), 20,809-20,824.

Kozian, W. 1994. Die großen Eistriften im südwestlichen Teil des Südatlantiks und vor Kap Horn. Deutsches Schiffahrtsarchiv, 17, 51-92.

Lemke, P., ed. 1994. The Expedition Antarktis X/4 of R/V "Polarstern" in 1992. Ber. Polarforsch./Rep. Pol. Res. 140.

Lemke, P., W. B. Owens and W.D. Hibler, III. 1990. A coupled sea icemixed layer-pycnocline model for the Weddell Sea. 7. Geophys. Res., 95(C6), 9513-9525.

Martinson, D. G., P. D. Killworth and A. L. Gordon. 1981. A convective model for the Weddell polynya. 7. Phys. Oceanogr., 11 (4), 466-488.

Muench, R. D. and A. L. Gordon. 1995. Circulation and transport of water along the western Weddell Sea margin. 7. Geophys. Res., 100 (C9), 18,503-18,515.

Nøst, O. and S. Østerhus. 1998. Impact of grounded icebergs on the hydrographic conditions near the Filchner Ice Shelf. In Jacobs, S. S. and R. F. Weiss, eds. Ocean, ice and atmosphere: interactions at the Antarctic continental margin. Washington, DC, American Geophysical Union, 267-284. (Antarctic Research Series 75.)

Schröder, M. and E. Fahrbach. 1999. On the structure and transport of the eastern Weddell Gyre. Deep-Sea Res., Ser. II, 46(1-2), 501-527.

Smetacek, V., H. J.W. de Baar, U.V. Bathmann, K. Lochte and M. M. Rutgers van der Loeff. 1997. Ecology and biochemistry of the Antarctic Circumpolar Current during austral spring: a summary of Southern Ocean JGOFS cruise ANT X/6 of R.V. Polarstern. Deep-Sea Res., Ser. II, 44(1-2), 1-21.

Smith, S. D. and E. G. Banke. 1983. The influence of winds, currents and towing forces on the drift of icebergs. Cold Reg. Sci. Technol., 6 (3), 241-255.

Viehoff, T. and A. Li. 1995. Iceberg observations and estimation of submarine ridges in the western Weddell Sea. Int. F. Remote Sensing, 16(17), 3391-3408. 